\title{
Gender, Age and Teaching Experiences Differences in Decision-Making Behaviours of Members of Selected Kenyan Secondary School Disciplinary Panels
}

\author{
Peter J. O. Aloka ${ }^{1} \&$ Olaniyi Bojuwoye ${ }^{1}$ \\ ${ }^{1}$ Department of Educational Psychology, University of the Western Cape, Bellville, South Africa \\ Correspondence: Peter J. O. Aloka, Department of Educational Psychology, University of the Western Cape, \\ Private Bag, X 17, Bellville 7535, South Africa. E-mail: jairopeteraloka@yahoo.com
}

Received: April 23, 2013 Accepted: June 4, 2013 Online Published: August 1, 2013

doi:10.5539/ass.v9n10p43 URL: http://dx.doi.org/10.5539/ass.v9n10p43

\begin{abstract}
The study investigated gender, age and teaching experiences differences in decision- making behaviours of members of selected Kenyan secondary school disciplinary panels.

Mixed Methods design was adopted for the study. Both quantitative and qualitative data were collected. Study sample comprised 78 participants drawn from ten secondary school disciplinary panels. Participants comprised 45 males and 33 females, clustered into four age groups of-29 years $(n=21), 30-39$ years $(n=28), 40-49$ years $(n=14)$, and 50-59 years $(n=15)$; and six teaching experience categories of $1-5$ years $(n=33), 6-10$ years $(n=14)$, $11-15$ years $(n=5), 16-20$ years $(n=6), 21-25$ years $(n=8)$, and $26-30$ years $(n=12)$.

Data analysis results revealed gender, age and experience differences in decision-making behaviours of members of disciplinary panels who participated in the study. Male participants were found to tend towards risky decision-making behaviours while female participants tended towards cautious decision-making behaviours. Younger and less experienced participants were also found to be risky in their decision-making behaviours also tended panel members made risky pre-disciplinary hearing decision-making behaviours, while their older and more experienced counterparts were more cautious. Based on the findings of this study it is recommended that, in order to cater for the diverse nature of student behaviour problems and to effectively manage the same, consideration must be given to delicate balance of age, gender and experience in the composition of members of a school disciplinary panel.
\end{abstract}

Keywords: gender, age, teaching experiences, types of decision-making behaviours, student behaviour problems, disciplinary panels, secondary schools

\section{Introduction}

Student behaviour management has become an important feature of every Kenyan secondary school (Aloka, 2012). This is an attempt to address ill-disciplined behaviours of secondary school students which have caused public concern or outcry and continued to feature more prominently in the national agenda of Kenya. The student behaviour problems constitute barriers to learning, make school unsafe and negatively impact learning and overall well-being of students and teachers. (Yahaya, Ramli, Hashim, Ibrahim, Rahman \& Yahaya, 2009) also note that students with behaviour problems come to school but they are not ready to learn, but interfere with the leaning of other students and the teaching of teachers. Ill-disciplined behaviours of students make school environment unsafe and thereby inhibiting the pursuance of the schools' major education objectives. Student behaviour problems are also thought to be precursor to later school dropout and similar negative social outcomes. There is currently the fear that students' behaviour problems could make Kenyan educational objectives unachievable leading to the possibility that schools may be incapable of producing fully functioning future adults and or good citizens capable of contributing to the nation's socio-economic development and quality of life of the people of Kenya (Aloka, 2012). Hence the need to evolve strategies to assist students to inculcate attitudes of respect for self, respect for the rights of others and for the school as well as the community in which the school is located (St Cyprian School, 2010). Schools are expected to evolve strategies for training students in skills to enable them to have greater sense of control over their behaviours and to be capable of living by rules-guided behaviours (Aloka, 2012; American Foundation of Teachers, 2010). 
In response to the challenges posed by student behaviour problems, the Kenyan Ministry of Education recommended several intervention initiatives for schools in order to address students' maladaptive behaviours and inculcate positive behaviours in the students. For example, Kenyan public schools are expected to constitute a disciplinary panel with the goal of ensuring appropriate and positive behaviour development of their students (Aloka, 2012). School disciplinary panels are to be made up of small group of teachers charged with the responsibility of making decisions for the management of students' behaviours, for ensuring safety of staff and students and for creating an environment conducive for teaching and learning (Mabena \& Princsloo, 2000; Joubert \& Rossouw, 2004). The employment of small group of teachers for making decisions for the management of student behaviours has several advantages over and above leaving such decisions to a single individual school principal. Greater number of approaches and alternatives to the solution of a problem are available in groups rather than with individual standing alone (Bojuwoye, 2002). Student behaviours continue to assuming complex proportion therefore their management requires specialized knowledge and skills in numerous areas usually not possessed by one person (Aloka, 2012; Bonito, 2011; Lunenberg, 2010). Thus, a school disciplinary panel, made up of small group of teachers, is an important institutional support structure for student behaviour development (Aloka, 2012).

Literature is replete with opinions regarding dimensions of student behaviours on which school disciplinary panels can make decisions. The authors of this article have clustered into four categories these dimensions as gleaned from suggestions and documents by the American Foundation of Teachers (2010) the Department of Education (2011), St Cyprian School (2010) and Yahaya, Ramli, Hashim, Ibrahim, Rahman and Yahaya (2009), These are:

1) whether or not a presenting student behaviour problem is a prohibited unacceptable behaviour as stipulated by the school rules and regulations;

2) whether or not the offending student is an habitual -ill-disciplined individual who ignores warnings or a first offender; whether or not the student problem behaviour has potential to cause or has caused disruption in relationships with other students or with the teachers; and,

3) Whether or not a student's problem behaviour has potential to negative impact the image or disciplinary tone of the school and, therefore cause serious embarrassment to the school.

A school disciplinary panel operates like a small social group during disciplinary hearing meetings when members of the panel engage themselves in dynamic interactions, share information, ideas or opinions as they critically analyze factors associated with presenting behaviour problem,of a student, brainstorm on alternative conclusions or decision-options related to the presenting behaviour problem and select what they jointly consider as the best decision-option or consensus decision that will best address the behaviour problem (Lizárraga et al., 2007). It is, therefore, safe to assume that the phenomenon of group polarization occurs during disciplinary hearing meeting when members of a school disciplinary panel discuss a student behaviour problem. Group polarization is a small group tendency that makes discussions in such group to intensify convergence of opinions (Kllein \& Olbrecht, 2011) Group polarization is the result of a shift from individually made pre-group meeting decisions to post-group meeting decisions concerning a group task (Friedkin \& Johnsen, 2011). Friedkin and Johnsen, (2011) also opine that during a group meeting members engage in dynamic interactions among themselves, share information, critically analyze issues related to their group task, brainstorm on alternative conclusions and select or settle upon one of the very many decision options available and collectively consider that option to be the decision of the group (Friedkin \& Johnsen, 2011).

Decisions of a small social group may be described as risky, extreme or cautious (Sobel, 2006). Risky or extreme decisions are those decisions which when applied to address a behaviour problem may be aversive, or counter-productive and may not lead to desired positive outcome(s) For instance, risky or extreme decision on a student behaviour problem may threaten or undermine the affected student's dignity, safety and fundamental rights (Joubert, de Waal \& Rossouw, 2004) Risky or extreme decisions may lead affected student to further commission of behaviour problems rather than facilitate the growth or development and the well-being of the student. On the other hand, cautious decisions, are those which take into consideration extraneous circumstances which may underlying a student behaviour problem and the goal of the implementation of cautious decisions is the avoidance of acts which may prevent the positive growth and or development of the student (Conkle, 2007).

An important factor in group decision-making is with regard to decision-making behaviours of group members. In group meetings group members are continuously concerned about their status in the group and are more motivated for approval by other members of the group (Grodzki, 2011). This is to state that group members often engage in behaviour tendency referred to as social comparison among themselves before making a decision 
(Mercier \& Sperber, 2011; Zhu, 2009). Apart from social comparison behaviour tendency group members are also influenced by the nature of information shared during group meetings Thus group members may be persuaded to change their original pre-group meeting individually made decisions on a group task depending on the nature of information shared. As asserted by Mercier and Sperber (2011) group members are influenced to change from their pre-group meeting individually-made decisions to post-group meeting collective or consensus group decision due to what is called persuasive arguments. As group members interact among themselves during a group meeting they freely exchange information which encourages or persuades them to shift their decisions towards a collective or consensus decision depending on the strength or persuasiveness of the arguments or the information shared (Zhu, 2009). Information shared during a group meeting may be described as persuasive depending on whether or not it is a new information not known until the group meeting and the information is perceived as credible or correct because it provides better understanding or comprehension and better insight into the group task (Mercier \& Sperber, 2011).

While both social comparison and persuasive arguments may influence group members' decision-making behaviours other factors identified as capable of influencing group members' decision-making behaviours are gender, age and experiences of members (Van Leijenhorst, Westenberg \& Crone, 2008; Ertac \& Gurdal, 2010; Leijenhorst, 2010).

\section{Material Studies}

Research on gender, age and experience differences in decision-making behaviours of members of a small group has been documented. However, most of the studies on decision-making behaviours of members of small groups have been carried out in experimental contexts, as well as in hypothetical situations, courts, business, financial and or investment contexts. Very scanty literature exists of studies that focused on educational institutions. Studies on gender differences in decision-making behaviours in different contexts, outside of education, have also been documented. For example, Van Leijenhorst, Westenberg \& Crone, (2008); Ertac \& Gurdal, (2010); Leijenhorst, (2010) all found that, at all ages, females are more risk-averse than males in their decision-making behaviours. Similarly, study by Pawlowski and Atal (2008) also revealed risky decision-making behaviour tendency among males more than among females.. Ertac and Gurdal (2012) and Charnessa \& Gneezy, (2012) all reported consistent results that, women appear to be more financially risk-averse than men. Other studies have reported that, during the process of group decision-making on a group task, women are less aggressive in their strategies as compared to men (Apesteguia, Azmat \& Iriberris, 2011). However, other studies on gender and types of decisions have reported mixed results (Arano, Parker \& Terry, 2010). For instance, Maccoby, (1998) refuted the commonly held belief that females are more easily influenced than are males during group decision making. One important limitation of the reported studies is that researchers considered different samples, for instance, they did not consider whether or not the males and females being researched were comparable to one another in their decision-making behaviours. Since the conclusions of previous research studies are mixed with regard to the gender differences in decision-making behaviours of members of small groups, the need for additional research in education setting is, therefore more apparent.

Studies on age differences in decision-making behaviours have also been documented. Chen and Ma, (2009) reported that, older adults' decision-making behaviours are significantly influenced by anticipated positive emotions, unlike those of the younger adults whose decision-making behaviours were found to be closely associated with anticipated negative emotions. Mata et al, (2011) also found that, older adults are more risk averse in comparison with younger people who make risky decisions. Rolison, Hanoch\& Wood, (2012); Gorlick, Lighthall, Burgeno, Schoeke and Ariely, (2012); Albert \& Duffy (2012) and Chen, Ma \& Pethtel, (2012) all concluded that older adults are more likely, than young adults, to choose cautious options in their decisions. Rana, Murtaza, Noor and Rehman, (2011) surmise that as age of an individual increases, risk perception during decision-making decreases. Aloka (2012) also contends that, for young people, quite a different picture presents itself, because their attitudinal structures are not well established, and new information may serve to complete a large segment of reference.

Age is related to experiences and the latter could also be a significant factor that may affect the decision-making behaviours of members of a small group. In this connection McIntyre, (2006) found that, most teachers who have just been posted to schools from universities have little skills in managing student behaviour and they mostly adopt negative views while addressing student behaviour problems while teachers with many years of teaching experiences are found to respond in proficient manner when dealing with students' behaviour problems. Experienced teachers' 'decision-making behaviours are also characterized by their being focused on the well-being, growth or progress of students while also acknowledging when students show an approximation of the expected behaviours. Day, Sammons, Stobart, Kingston, and Gu, (2007) found less experienced teachers to 
struggle more in their decision-making behaviours regarding management of students ill-behaviours in schools. Tsouloupas(2011) found that more experienced teachers have higher self-beliefs in their abilities to control their class and manage challenging student-behaviours, while less experienced teachers feel ineffective or less confident in their abilities to deal with student problem-behaviours.

Most of the previous studies on gender, age and experience differences in decision-making behaviours of members of small groups were carried out in contexts such as in business investments, lottery games, family and hypothetical contexts. However, not many study have been found to have addressed gender and age differences in decision- making behaviours of members of school disciplinary panels. In addition, previous studies on the effects of teaching experiences on decision-making behaviours have focused on how different teachers handle student disciplinary problems, but very scanty literature was found to have addressed types of decisions in school disciplinary panels. The intent of the current study is to fill these gaps in literature.

The current study explored gender, age and teaching experiences differences in decision-making behaviours of members of the Kenyan secondary school disciplinary panels. The following hypotheses were tested by the study:

1) There is no statistically significant gender, differences in decision-making behaviours of members of Kenyan secondary school disciplinary panels.

2) There are no statistically significant age differences in decision-making behaviours of members of Kenyan secondary school disciplinary panels.

3) There are no statistically significant differences in the decision-making behaviours of members of Kenyan secondary school disciplinary panels on the bases of their teaching experiences.

Also a research question was advanced to guide the study and this is as follows:

Are there gender, age and teaching experiences differences in the decision-making behaviours of members of Kenyan secondary school disciplinary panels?

\section{Area Description}

The study was limited to ten selected secondary schools in Rongo district of Kenya. The district has three categories of secondary schools, namely, Boys' Only, Girls Only and Co-educational schools.

\section{Methods}

\subsection{Research Design}

The study adopted Mixed Methods research approach and gathered both quantitative and qualitative data. Mixing together both quantitative and qualitative techniques made it possible to arrive at richer and more complete description covering fairly all aspects of the phenomenon under investigation. Johnson \& Onwuegbuzie (2004) and Morgan (2007) reiterate that, the use of both quantitative and qualitative methods provides more insights and understanding that can be missed if only one method is used. The quantitative aspect was used to ascertain whether or not gender, age and teaching experiences differences in decision-making behaviours existed among panel members of Kenyan secondary school disciplinary panels. The qualitative aspect was with regards to panel members' interpretations and or meanings they make of the experiences in disciplinary hearing meetings which might have led to shifts or changes in their decision-making behaviours.

\subsection{Participants}

The population for the study comprised teachers who were members of their schools' disciplinary panels. The sample size for the study comprised 78 teachers made up of 45 males and 33 females belonging to varying age groups such as ages: 20 to 29 years old $(n=21), 30-39$ years old $(n=28), 40-49$ years old $(n=14)$, and 50-59 years old $(n=15)$. The participants' distributions on the basis of teaching experiences are: 1-5 years teaching experiences $(n=33), 6-10$ years $(n=14), 11-15$ years $(n=15), 16-20$ years $(n=6), 21-25$ years $(n=8)$, and 26-30 years $(n=12)$.

For the qualitative phase of the study, a sample size, (n) of ten panel members (one participant from each school) was selected for semi-structured interviews using the purposive sampling technique. When selecting the ten teachers, factors such as the age, years of teaching experience, positions of responsibility in school and school categories of the panel members were taken into consideration.

\subsection{Measuring Instruments}

The Demographic Questionnaire and Modified Choice Dilemma Questionnaire (MCDQ) were used for collecting quantitative data. The Demographic Questionnaire collected information relevant to the personal 
characteristics of the participants including gender, age and years of teaching experiences. The MCDQ was used for quantitative estimation of the shifts from pre to post disciplinary hearing decisions (Aloka, 2012). The original Modified Choice Dilemma Questionnaire (MDCQ) was developed by Stoner (Ronay \& Kim, 2006) and is among the most frequently used techniques for estimating, in quantitative terms, changes in decisions by individuals before and after group deliberations or meetings (Appelt, Milch, Handgraaf \& Weber, 2011). The questionnaire has response options for rating decisions by choosing between the odds of $1,3,5,7$ or 9 in 10 chances (Freedman, 2007). The respondents of this study were requested to rate their decision-making behaviours taking into consideration the four dimensions of the presenting student behaviour problem - that is, the types of presenting student behaviour problems, the characteristic behaviour tendencies of the misbehaving students, the effects of the behaviours problem on the relationships between the misbehaving students and others and the effects of presenting student behaviour problems on the disciplinary tones of the schools.

The Modified Choice Dilemma questionnaire had response options from which participants were to choose one option from the five presented on the questionnaire in response to each statement on the questionnaire. The options were with regard to whether there was one in ten chances, three in ten chances, five in ten chances, seven in ten chances or nine in ten chances the option fits their decisions pertaining to the dimensions of the presenting student behaviour problem on which decisions were to be made.. The validity of the instruments was ascertained by making clear statements about the aspects on the sub-scale that influenced the panel members' decisions, and this was confirmed by a panel of judges who are psychologists and experts in group dynamics. The internal reliability co-efficient estimate reported for the MDCQ was Cronbach's alpha of 0.608 , and was considered to be adequate 0.500 (Aloka, 2012).

To assess the panel members 'meanings and or interpretations of their experiences during disciplinary hearing meetings the semi-structured interviews were used. Trustworthiness of the qualitative data was assured by visiting the participating schools prior to the actual commencement of the study. The visits were to inform prospective participants about the study (purpose, conditions for participation) and, to solicit for support for participating in the study. The visit also helped to gain adequate understanding of the environment. The semi structured interviews allowed the researcher to follow ideas, to probe responses and to investigate motives and feelings of the participants

\section{4 Procedure}

The ethical clearance was first obtained from the University of the Western Cape Senate Research Ethics Committee. Thereafter, permission to carry out the study in Kenya was obtained from the Ministry of Education, principals, and teacher-members of disciplinary panels of the selected secondary schools in Rongo district. Upon consenting to participate in the study, (by signing the informed consent form) the Questionnaires were administered to the participants before and after the disciplinary hearing meetings. The questionnaires were first administered individually to the members of disciplinary panels just before each disciplinary hearing meeting, in order to obtain participants' pre-group meeting decisions on the four dimensions of the presenting student behaviour problems. After the disciplinary hearing meetings, the participants were then given fresh but new Demographic and Modified Choice Dilemma Questionnaires to complete and to indicate their post-disciplinary hearing decisions. The total administration of the questionnaires was approximately 15 to 20 minutes each for the pre and post disciplinary sessions.

Qualitative data was collected using in-depth individual one-on-one interviews in secluded rooms where the participants' were assured of confidentiality and privacy of information that was to be collected. The interview process allows researchers to observe and ask questions thus providing opportunity to look at issues as if through the eyes of the participants (Bojuwoye \&Akpan, 2009). Each interview session for each of the ten selected participants lasted about 30-45 minutes. Thereafter, participants were each given time to ask questions after the interview sessions.

\subsection{Data Analysis}

Descriptive statistics were determined for all measures on pre and post disciplinary hearing response scores of participants on the four dimensions of the presenting student behaviour problems. Participants' pre- and postdisciplinary hearing response scores on the MCDQ were found and the differences between the pre- and post-disciplinary hearing response scores were calculated, To test the hypotheses advanced for the study the data were then subjected to Analysis of Variance, ANOVA, test (for gender differences) and Multivariate Analysis of Variance, MANOVA, (for age and teaching experiences sub-groups) to determine significant differences between pre- and post-response scores on the MCEDQ and significant statistical differences among subgroups of participants. Quantitative data was analyzed using the Statistical Package for Social Sciences (SPSS). 
Further analysis of data was performed by use of tests of between-subjects to locate where the differences lie on the basis of the factors associated with the disciplinary problems. Post Hoc Multiple Comparisons test was then carried out to locate exactly on which factors associated with disciplinary problems where the differences lie. The $p$-value is a criterion of this nature, and it indicates a probability that the null hypothesis is incorrectly rejected. For the purposes of this study, differences were regarded as statistically significant when the p-value was less than 0.05 .

Qualitative data analysis was carried out by engaging in multiple readings of the interview transcripts and reviewing data in order to facilitate initial interpretations of participants' responses. Emerging patterns of responses were found and these participants' response patterns form the themes from which information for answering the research question was found.

\section{Results}

In terms of the results of the of the quantitative data analysis, Table 1 presents the descriptive statistics of the pre and post-disciplinary hearing meetings' mean response scores on the MCDQ and the estimated differences between the pre and post disciplinary hearing meetings' mean response scores. Table 2 presents the summary results of ANOVA for the results of Hypothesis 1 on gender differences in participants' decision-decision making behaviours. Table 3 displays the results of MANOVA for the results of Hypotheses 2 and 3 on age and experiences differences in decision-making behaviours.

Descriptive statistics of the response scores regarding pre and post disciplinary hearing decisions are presented in Table 1.

Table 1. Pre- and post-response score on dimensions of presenting behaviour problems and estimated differences

\begin{tabular}{|c|c|c|c|c|c|c|c|c|c|c|c|c|c|c|}
\hline \multirow[t]{2}{*}{ Variables } & & \multirow[t]{2}{*}{$\mathbf{N}$} & \multicolumn{3}{|c|}{$\begin{array}{l}\text { Types of the disciplinary } \\
\text { problems }\end{array}$} & \multicolumn{3}{|c|}{$\begin{array}{c}\text { Behaviour } \\
\text { characteristics of the } \\
\text { offender }\end{array}$} & \multicolumn{3}{|c|}{$\begin{array}{l}\text { Effects of disciplinary } \\
\text { problem on relationship } \\
\text { with peers \& teachers }\end{array}$} & \multicolumn{3}{|c|}{$\begin{array}{l}\text { Effects of behaviour } \\
\text { problems on disciplinary } \\
\text { tone of the school }\end{array}$} \\
\hline & & & pre & post & $\begin{array}{l}\text { Estimated } \\
\text { differences }\end{array}$ & pre & post & $\begin{array}{l}\text { Estimated } \\
\text { differences }\end{array}$ & pre & post & $\begin{array}{l}\text { Estimated } \\
\text { differences }\end{array}$ & pre & post & $\begin{array}{l}\text { Estimated } \\
\text { differences }\end{array}$ \\
\hline \multirow[t]{2}{*}{ Gender } & Male & 45 & 6.64 & 5.25 & 1.39 & 4.87 & 6.02 & 0.80 & 5.13 & 2.59 & 2.54 & 5.98 & 2.56 & 3.42 \\
\hline & Female & 33 & 3.29 & 6.02 & 2.73 & 3.35 & 4.07 & 2.32 & 2.60 & 6.59 & 3.99 & 2.20 & 5.77 & 3.57 \\
\hline \multirow[t]{4}{*}{$\begin{array}{l}\text { Age groups of } \\
\text { panel members }\end{array}$} & $\begin{array}{l}20-29 \\
\text { years }\end{array}$ & 21 & 7.41 & 3.56 & 4.45 & 7.87 & 2.56 & 5.31 & 7.54 & 2.36 & 5.18 & 6.98 & 3.32 & 3.66 \\
\hline & $\begin{array}{l}30-39 \\
\text { years }\end{array}$ & 28 & 6.95 & 2.05 & 4.90 & 5.54 & 1.95 & 3.59 & 7.87 & 3.81 & 4.06 & 6.58 & 4.27 & 2.31 \\
\hline & $\begin{array}{l}40-49 \\
\text { years }\end{array}$ & 14 & 5.11 & 3.55 & 1.56 & 2.58 & 5.56 & 2.40 & 6.10 & 3.42 & 2.60 & 1.69 & 3.69 & 2.00 \\
\hline & $\begin{array}{l}50-59 \\
\text { years }\end{array}$ & 15 & 2.30 & 3.65 & 1.35 & 2.21 & 4.10 & 1.89 & 2.55 & 3.14 & 0.59 & 1.22 & 3.26 & 2.04 \\
\hline \multirow{6}{*}{$\begin{array}{l}\text { Years of } \\
\text { teaching } \\
\text { experiences of } \\
\text { panel members }\end{array}$} & $\begin{array}{l}1-5 \\
\text { years }\end{array}$ & 33 & 6.52 & 2.56 & 4.26 & 6.87 & 1.56 & 5.31 & 7.45 & 3.12 & 4.33 & 8.12 & 1.94 & 6.18 \\
\hline & $\begin{array}{l}6-10 \\
\text { years }\end{array}$ & 14 & 7.85 & 3.20 & 4.65 & 7.75 & 2.95 & 4.80 & 6.58 & 4.27 & 2.31 & 6.25 & 3.81 & 2.44 \\
\hline & $\begin{array}{l}11-15 \\
\text { years }\end{array}$ & 5 & 4.56 & 6.68 & 2.12 & 2.50 & 5.69 & 3.19 & 6.98 & 4.10 & 2.08 & 7.42 & 3.06 & 4.36 \\
\hline & $\begin{array}{l}16-20 \\
\text { years }\end{array}$ & 6 & 3.34 & 5.58 & 2.24 & 3.32 & 5.92 & 2.60 & 3.23 & 6.56 & 3.33 & 4.63 & 7.13 & 2.50 \\
\hline & $\begin{array}{l}21-25 \\
\text { years }\end{array}$ & 8 & 2.45 & 4.05 & 1.60 & 2.67 & 4.02 & 2.02 & 1.68 & 3.64 & 1.96 & 4.42 & 5.76 & 1.34 \\
\hline & $\begin{array}{l}26-30 \\
\text { years }\end{array}$ & 12 & 2.34 & 3.67 & 1.33 & 2.21 & 4.23 & 1.35 & 1.23 & 2.20 & 0.97 & 2.25 & 3.26 & 1.01 \\
\hline
\end{tabular}


According to the information displayed on Table 1, the estimated pre disciplinary hearing response scores of male members of the disciplinary panels were generally relatively higher than those of their female counterparts in each of the four dimensions of presenting behaviour problems on which decisions were to be made. High male participants' scores on MCDQ are indications that male participants made risky pre-disciplinary hearing decisions as compared to the females who made cautious pre-disciplinary hearing decisions. The table also shows that female members of the Kenyan secondary school disciplinary panels made greater shifts from pre to post disciplinary hearing meeting decisions than their male counterparts in all the four dimensions of presenting student behaviour problems on which decisions were to be made. This is an indication that the male members made relative little or no shift from their original pre-disciplinary hearing individually-made decisions as compared with their female counterparts.

The information also indicates that, generally, for decisions on all dimensions of presenting student behaviour problems, the younger and less experienced panel members had the highest pre disciplinary hearing response scores, while the older more experienced panel members had the lowest pre- disciplinary hearing response scores. This may means that younger participants made risky pre-disciplinary hearing decisions while older members made cautious disciplinary hearing decisions. The information also indicates that older more experienced members; in comparison to other categories of participants had least estimated measures regarding the differences in the shifts from pre to post disciplinary hearing decisions, whereas younger and less experienced panel members made greater shifts from their pre to post disciplinary hearing decisions.

To test whether there were statistically significant differences in the pre and post disciplinary hearing decisions between the male and female respondents, a one way Analysis of Variance (ANOVA) was performed on the scores. The ANOVA results indicated probability level to be $\mathrm{P}=0.000$ which is less than five percent $(0.05$ or $\mathrm{P}<$ 0.05) (Table 2). This is an indication that significant differences exist in the types of pre to post disciplinary hearing decisions between the male and female members of the selected Kenyan Secondary School disciplinary panels.

Table 2. ANOVA summary results of the differences in the pre and post disciplinary hearing response scores of male and female respondents

\begin{tabular}{lccccc}
\hline & Sum of Squares & Df & Mean Square & F & Sig. \\
\hline Between groups & 437.91 & 1 & 437.91 & 13.96 & $0.000^{*}$ \\
Within groups & 2383.89 & 76 & 31.37 & & \\
Total & 2821.80 & 77 & & & \\
\hline
\end{tabular}

The Multivariate Analysis of Variance (MANOVA) statistical performed to test whether the estimated mean differences in the of pre and post disciplinary hearing decisions, on the basis of the age groups, revealed statistically significant differences (Wilk's Lambda $(\lambda)$ test : F $(12,188)=7.40, P=0.000, P<0.05$ ) (Table 3). The MANOVA statistical test also revealed statistically significant differences in the types of pre to post disciplinary hearing decisions, on the basis of the teaching experiences of members of the disciplinary panels (Wilk's Lambda $(\lambda)$ test: $\mathrm{F}(20,230)=5.33, \mathrm{P}=0.000, \mathrm{P}<0.05)$ (Table 3). This means that factors of gender, age groups and teaching experiences of panel members influenced the decisions-making behaviours of the participants.

Table 3. Summary results of MANOVA test performed one the pre and post disciplinary hearing response scores on the basis of age and teaching experiences groups

\begin{tabular}{|c|c|c|c|c|c|c|}
\hline Effect & MANOVA test & Value & $\mathbf{F}$ & Hypothesis df & Error df & Sig. \\
\hline \multirow{4}{*}{$\begin{array}{l}\text { Age groups of the panel } \\
\text { members }\end{array}$} & Pillai’s Trace & 0.718 & 5.738 & 12.00 & 219.00 & $0.000^{*}$ \\
\hline & Wilk's Lambda & 0.360 & 7.400 & 12.00 & 188.00 & $0.000 *$ \\
\hline & Hotelling's Trace & 1.570 & 9.117 & 12.00 & 209.00 & $0.000 *$ \\
\hline & Roy's Largest Root & 1.247 & 2.605 & 4.00 & 73.00 & $0.000 *$ \\
\hline \multirow{4}{*}{$\begin{array}{l}\text { Category of years of } \\
\text { teaching experiences }\end{array}$} & Pillai's Trace test & 0.857 & 3.92 & 20.00 & 288.00 & 0.000 \\
\hline & Wilk's Lambda test & 0.282 & 5.33 & 20.00 & 230.00 & $0.000 *$ \\
\hline & Hotelling's Trace test & 2.059 & 6.94 & 20.00 & 270.00 & 0.000 \\
\hline & Roy's Largest Root test & 1.804 & 25.97 & 5.000 & 72.000 & 0.000 \\
\hline
\end{tabular}


Further analysis of data was performed by use of tests of between-subjects to locate where the differences lie on the basis of the dimension of presenting student behaviour problems. The results of MANOVA tests of between subjects as displayed in Table 4. The results indicate statistically significant differences among the disciplinary panel members of the four age groups regarding the pre to post disciplinary hearing decisions on the four dimensions of presenting student behaviour problems on which decisions were made, - types of presenting student behaviour problems $=[\mathrm{F}(3,72)=18.19 ; \mathrm{P}=0.000, \mathrm{P}<0.05]$, the behaviour characteristics of the offender $=[\mathrm{F}(3,72)=15.40 ; \mathrm{P}=0.000, \mathrm{P}<0.05]$, the effects of the student behaviour problems on the offending students' relationships with peers and teachers $=[\mathrm{F}(3,72)=16.67 ; \mathrm{P}=0.000, \mathrm{P}<0.05]$, and effects of the presenting behaviour problems on the disciplinary tones of the schools $=[\mathrm{F}(3,72)=4.19 ; \mathrm{P}=0.000, \mathrm{P}<$ 0.05] (Table 3). Further Scheffe's Post Hoc test results also indicated that panel members of the age groups 40-49 years and 50-59 years made cautious pre-disciplinary hearing decisions, as compared to those in 20-29 and 30-39 years of age categories who made risky pre-disciplinary hearing decisions.

Further analysis to establish where the significant differences in participants' decision-making behaviours lie, was performed by use of tests of between-subjects to ascertain where significant differences lie on the effect of years of teaching experiences of panel members. The results indicate that, statistically significant differences exist among the panel members of the six categories of years of teaching experiences on all the four dimensions of the presenting student behaviour problems.s on which decisions were to be made -, the types of presenting student behaviour problems $=\mathrm{F}(5,72)=13.66 ; P=0.000, P<0.05]$; the behaviour characteristics of the offenders $=[\mathrm{F}(5,72)=12.94 ; P=0.000, P<0.05]$; the effects of presenting student behaviour problems on the offending students' relationships with peers and teachers $=[\mathrm{F}(5,72)=9.678 ; P=0.000, P<0.05]$; and the effects of presenting student behaviour problems on the images or disciplinary tones of the schools $=[\mathrm{F}(5,72)=$ 3.283; $P=0.000, P<0.05]$.

The Scheffe's Post Hoc test results further indicate that participants with less years of teaching experiences (categories 1-5, 6-10 years) differed in their decision-making behaviours when compared to members with more years of teaching experiences (categories 21-25, 26-30 years). Less experienced teachers were also greatly influenced by the factors in the dynamic interactions among panel members during disciplinary hearing meetings. The more experienced participants appeared to be rather reluctant in yielding their original positions.

In general, the results of the quantitative data analysis revealed significant gender, age and teaching experience differences in decision-making behaviours of participants on all the four dimensions of presenting student behaviour problems on which decisions were to be made. The dimensions of presenting student behaviour problems include- the types of presenting student behaviour problems, the behaviour characteristics of offending students, the offending students relationships with their peers and teachers, and the image or disciplinary tones of the schools.

\subsection{Qualitative Results on Age and Teaching Experiences Differences in the Types of Disciplinary Hearing Decisions}

Qualitative data obtained using interviews were analyzed using thematic framework and emerging themes from reported participants' experiences especially with regard to shifts or changes in the participants' decision-making behaviours from pre-disciplinary hearing individually made decisions to post-disciplinary hearing group decisions. The results of thematic analyses further revealed that younger participants reported more shifts or changes in their decision-making behaviours in comparison to the older more experienced participants when at the disciplinary hearing meetings, older participants offer new information on the behaviour problems, Major influences of older members on younger members of the disciplinary panels, which were reported during interviews are related to the age and teaching experiences of the older members. Respect for age is an important factor to younger members of the disciplinary panels. The perceived wealth of experience of older members and the notion that age closely associated with wisdom are factors reported to have played significant influences on younger members. Whenever older and more experienced members of the disciplinary panels offer information or opinions during disciplinary hearings, the younger members responded by shifting from their pre-disciplinary hearing individually made decisions to group decisions greatly influenced by the older and more experienced members.

This behaviour tendency in decision making may also be due to the reluctant of more experienced and older members' refusal to change their pre-disciplinary hearing decisions Older more experienced members often perceive the younger members as lacking in experience and less mature when it comes to dealing with disciplinary problems of students. An important consider which older members reported during interviews is the with regard to decision-making behaviours of younger members who always end up making more risky 
decisions without careful analysis of the context in which students present with misconduct or behaviour problems. . Older and more experienced members who have built their reputation take it upon themselves to protect the offending students from the negative consequences of risky decisions. Deference to age and experience as practiced by younger less experienced members of disciplinary panels result from upward or hierarchical comparisons. Younger participants, during group meetings reported comparing their opinions with those of the other panel members who they considered to be more senior to them and therefore, more knowledgeable (vertical/upward comparison) because of their positions, age and teaching experiences. Age and years of teaching experiences also influenced upward comparison among members leading to shifts from risky pre-disciplinary hearing to cautious post-disciplinary hearing decisions, due to the type of disciplinary problem treated, and effect of the problem on the disciplinary tone of the school. This resulted from the social comparison with other panel members who were respected by virtue of their age, position in school or years of teaching experiences. Some selected experts from interview transcripts regarding effects of age and teaching experiences of panel members on shifts to different types of disciplinary decisions is presented in the table 4 .

Table 4. Participants statements on effects of age groups and teaching experiences of panel members on shift in types of disciplinary decisions

\section{Factors $\quad$ Excerpts from Interview Transcripts}

\begin{tabular}{ll} 
& Age of panel members \\
\hline Persuasive & "My decision changed because of the \\
Argument and & opinions of a member who has been teaching \\
shifts in types & for many years and has been a member of \\
of decisions & $\begin{array}{l}\text { the school's disciplinary panel longer than } \\
\text { the rest of us. }\end{array}$
\end{tabular}

I changed my decision as the opinion offered by a more older member about an ill-disciplined student made me look at the case differently"

"My decision changed when additional information about the student offered an older member of the panel indicated that a student caught vandalizing fellow-students items"

Social
Comparison
and shifts in
types of
decisions

"My decision shifted and I agreed with the decision to make the girl undergo counseling in school came from older panel members who felt that the girl needed to be in school at this time that the offence was committed to suit for her final examinations"

"I did not change my earlier decision because the younger panel members were only interested in suspending the student instead of helping him reform in school"

"I realized that the older members were of the opinion of sending the student for counseling and monitoring the student closely during the examinations period so that he could complete schooling and I regarded their decision as more wise in taking care of the students circumstances"

\section{Teaching experiences}

"My decision to suspend the student was because of the information about the boy that was provided by the Deputy Principal who indicated that from her records, the boy had bullied other students before, and that the student had served a suspension for same offence"

"My decision changed because the information that the senior teacher presented was true and reflected that the boy is adamant not wanting to change from his past mistakes"

"I changed my decision because one of us who had taught for long confirmed it to be a case of mistaken identity"

"I changed my decision and agreed with other panel members who had been in the teaching profession for a long time who argued that suspending the girl when examinations were about to begin would make her drop out of school"

" $i$ changed my decision and agreed with the chairperson of the panel who insisted that since there is a growing case of senior boys bullying junior boys such should not be tolerated and that a strong warning be sent to other senior boys by suspending the offender" "my decision changed when i realized that the older members were of the opinion of sending the student for counseling and monitoring the student closely during the examinations period so that he could complete schooling and I regarded their decision as more wise in taking care of the students circumstances" 
Generally, the results revealed the influences of, older and more experienced panel members on other members of the panels. Data collected by Interviews show that the older and more experienced members of disciplinary data influenced the disciplinary decisions when, from their experiences, they gave opinions to the effect that, top-down control of adolescent behaviours could be counter-productive. At times, shifts also occurred when older panel members gave opinions that in certain problem behaviour cases, flexibility in the application of sanction was more practicable and capable of impacting positively on behaviour development of students than strictly applying sanctions. In other instances, the older members considered cognitive humanistic behaviour modification strategies (reward or positive reinforcement) to strict punishment. From the above findings, the shifts from pre-disciplinary hearing risky to post-disciplinary hearing cautious decisions occurred when the panel members felt that the nature of the disciplinary problem was not grievous, or when the members saw their role as not just dishing out punishment but also that of using decision to provide intervention in the form of support to reform the offender. The panel members also made cautious decisions when they felt that the new information led them to better understanding of the reason behind the offenders' behaviour patterns or misconducts, e.g. family background information, when the panel members felt that the nature of the disciplinary problem was not grievous, or when the members saw their role as not just dishing out punishment but also that of using decision to provide intervention in the form of support to reform the offender. Risky panel decisions on behaviour problems as expected by school policy may serve to protect the school's image but destroy the students, whereas, cautious decisions taken to develop the students behaviourally may also eventually promote the school's image.

\section{Discussion}

The purpose of this study was to explore influences of gender, age and teaching experiences on decision-making behaviours of members of Kenya secondary school disciplinary panels. The results of the analysis of quantitative data gathered for the study revealed that changes in decision-making behaviours of participants occurred from pre-disciplinary hearing individually made decisions to post-disciplinary hearing group decisions. The magnitude of the changes in decision-making behaviour however varies from one population group or the other.

In terms of gender differences in the decision-making behaviours of participants the results showed that female participants reported greater shifts or changes in their decision-making behaviours than their male counterparts. Female participants were found to make cautious decisions while male participants made more risky decisions. This finding on gender differences in decision-making behaviours is consistent with what exists in the literature. Studies by Van Leijenhorst, Westenberg \& Crone (2008); Ertac \& Gurdal, (2010) and Leijenhorst, (2010) all revealed that at all ages, females are more risk-averse than males in their $\mathrm{f}$ decision-making behaviours. According to Apesteguia, Azmat and Iriberris, (2011 an important reason for gender differences in decision-making behaviour in small social group process is that during group decision making process, women are less aggressive in their strategies as compared to men. Studies by Lizárraga, et al, (2007) and Apesteguia, et $a l$, (2011) all conclude that men, relative to women, are more assertive, controlling and aggressive in their attempt to persuade people to go along with them when making decisions . Asiyanbola (2005) also asserts that the differences in the decision- making behaviours between men and women could also be because of the deference to men by women, related social norms and stereotypes transmitted in the form of values, traditions, and behavioural expectations in indigenous or traditional societies. However,the assertion by Liu et al (2007) is that when women perform a group decision-making task, they foster cooperation and connection within the group, and tend to reserve their opinions and compromise their stands to complete the task while men, tend to contribute somewhat independently and ignore other's idea, hence women's willingness to be easily influenced to change decisions when compared with men.

The aim of the study was to find out if gender, age and teaching experiences differences existed in the types of disciplinary decisions among members of the Kenyan secondary school disciplinary panels. Gender, age and teaching experiences were found to be significant factors in the disciplinary panels' decisions. That is, depending on their gender, ages and teaching experiences, the participants do not behave in the same way in the dynamic interactions during disciplinary hearings leading to different types of decisions made by panel members. There are disparities between male and female, younger and older and less experienced and more experienced panel members as study found that female members tended to make cautious decisions in comparison with their male counterparts, younger and less experienced members tended to make risky or extreme decisions in comparison with their older and more experienced counterparts who tended to make more cautious decision. Furthermore, female, younger and less experienced members of the disciplinary panels were found to be more willing to be influenced by the factors in the dynamic interactions of the disciplinary panel group processes leading them to make greater shifts from pre-disciplinary hearing individual decisions to post disciplinary hearing group decisions than the male, older and more experienced members of the disciplinary panels who were more 
reluctant to shift from their pre-disciplinary hearing individual decisions to post disciplinary hearing group decisions.

The finding on age differences in decision-making behaviours are also consistent with study findings by Schlottmann, (2000); Harbaugh, et al, (2002);Manning, et al, (2004) and Levin, et al, (2007) t that young people make more risky decisions than adults. Study by Rolison, Hanoch and Wood (2012) revealed that younger adults are more willing to take risk, while older adults are more cautious. Albert and Duffy (2012) assert that older adults are more risk averse than young people.

Explanations given in the literature for teaching experiences differences in decision-making behaviours of teachers is that less experienced teachers lack self-efficacy (Rushton, 2000), doubt their capability (Onafowora, 2004), lack knowledge (Almog \& Shechtman, 2007) and are unaware of the necessary resources to successfully manage students' problems. On the other hand, more experienced teachers tend to have higher self-beliefs in their abilities to control their class and manage challenging student behaviours while less experienced teachers often feel less ineffective in their ability to deal with student mis-behaviours in schools. According to Swanson, et al, (1990) expert teachers have a well-established procedural plan for solving discipline problems and may therefore divert more of their attention to adequately defining the problem when compared to the novice teachers.

\section{Conclusion}

The study revealed that gender, age and teaching experiences are very important factors in decision-making behaviours of teacher-members of Kenyan secondary school disciplinary panels. Decision-making behaviours vary depending on gender, age and teaching experiences of individuals making the decision.. Therefore, major implication of this study's findings is with regard to the composition of schools' disciplinary panels, Human behaviour is complex and managing students' behaviours and, in particular, dealing with student misbehaviours requires skills, values and appropriate behaviours as well as experience in order to manage efficiently (Egyed \& Short, 2006). Some student behaviour problems would attract extreme or risky decisions while some others would attract cautious decisions. Therefore, to cater for the diverse nature of student behaviour problems and for effective management of the same consideration should be given to delicate balance of gender, age and teaching experiences in the composition of members of schools' disciplinary panels

One limitation of the study was that only one district was chosen. Schools outside the district probably may reflect other environmental characteristics which may not be present in Rongo district which may have influenced the characteristics of the participants and hence the outcomes of the study. One recommendation for further research is to investigate other personal and external factors that may play significant influences in decision-making behaviours of members of schools' disciplinary panels.

\section{Acknowledgements}

The writing of paper has been supported by University of the Western Cape Postgraduate Writing Fellowship.

\section{References}

Albert, S. M., \& Duffy, J. (2012). Differences in risk aversion between young and older adults. Neuroscience and Neuroeconomics, 1, 3-9. http://dx.doi.org/10.2147/NAN.S27184

Aloka, P. J. O. (2012). Group polarization in decision making: a study of selected secondary school disciplinary panels in Rongo district of Kenya. Unpublished $\mathrm{PhD}$ thesis, Faculty of Education of the University of the Western Cape.

Apesteguía, J., Azmat, G., \& Iriberri, N. (2011). The impact of gender composition on team performance and decision-making: Evidence from the field. Management Science.

Boateng, W. (2012). Evaluating the efficacy of focus group discussion (FGD) in qualitative social research. International Journal of Business and Social Science, 3(7), 54-57.

Bojuwoye, O. (1997). Student counseling services in a Nigerian University. International Journal for the Advancement of Counseling, 19, 41-53. http://dx.doi.org/10.1007/BF00121006

Boyer, L. (2012).Managing conflict: What to do and how to do it. Bradenton, Sarasota FL Leadership Options, LLC.

Charnessa, G., \& Gneezy, U. (2012). Strong Evidence for Gender Differences in Risk Taking. Journal of Economic Behavior \& Organization, 83(1), 50-58. http://dx.doi.org/10.1016/j.jebo.2011.06.007

Chen, Y., Ma, X., \& Pethtel, O. (2012). Age differences in trade-off decisions: Older adults prefer choice deferral. 
Psychology and Aging, 26(2), 269-273. http://dx.doi.org/10.1037/a0021582

Conkle, A. (2007). Decisions, decisions. Association for psychological science observer. Retrieved September 10, 2011, from http://www.psychologicalscience.org/observer/get/article.cfm?id=2191

Corcoran, K., Crusius, J., \& Mussweiler, T. (2011). Social comparison: Motives, standards, and mechanisms. In D. Chadee (Ed.), Theories in Social Psychology (pp. 119-139). Oxford: Blackwell Publishing Ltd.

Day, C. W., Sammons, P., Stobart, G., Kington, A., \& Gu, Q. (2007). Teachers matter. McGraw Hill.

Durlak, J. A., Weissberg, R. P., Dymnicki, A. B., Taylor, R. D., \& Schellinger, K. B. (2011). The impact of enhancing students' social and emotional learning: A meta-analysis of school-based universal interventions. Child Development, 82(1), 405-432. http://dx.doi.org/10.1111/j.1467-8624.2010.01564.x

Egyed, C. J., \& Short, R. J. (2006).Teacher self-efficacy, burnout, experience and decision to refer a disruptive student. School Psychology International, 27, 462-474. http://dx.doi.org/10.1177/0143034306070432

Ertac, S., \& Gurdal, M. Y. (2010). Deciding to decide: gender, leadership and risk-taking in groups. TÜSİAD-Koç University Economic Research Forum working paper series, No. 1028. Retrieved from http://hdl.handle.net/10419/45421

Ertac, S., \& Gurdal, M. Y. (2012). Personality, Group Decision-Making and Leadership. Retrieved September, 2012 from http://home.ku.edu.tr/ sertac/Personality.pdf.

Friedkin, N. E., \&Johnsen, E. C. (2011). Social Influence Network Theory: A Sociological Examination of Small Group Dynamics. Cambridge University Press. http://dx.doi.org/10.1017/CBO9780511976735

Grodzki, J. S. (2011). Role identity: At the intersection of organizational socialization and individual sense making of new principals and vice-principals. Canadian Journal of Educational Administration and Policy, (127). Retrieved December 30, 2011, from http://www.umanitoba.ca/publications/cjeap/pdf_files/grodzki.pdf

Hawkins, K., \& Power, C. B. (1999). Gender differences in questions asked during small decision-making group discussions. Small Group Research, 30(2), 235-256. http://dx.doi.org/10.1177/104649649903000205

Joubbert, R., de Waal, E., \& Rossouw, J. P. (2004). Discipline: Impact on access to equal educational opportunities. Perspectives in Education, 22(3), 77-87.

Kim, S., \& Hasher, L. (2005). The attraction effect in decision making: Superior performance by older adults. Journal of Experimental Psychology Section A, 58(1), 120-133. http://dx.doi.org/10.1080/02724980443000160

Leijenhorst, L. (2010). A developmental study of risky decisions on the Cake Gambling Task; Age and gender analyses of probability estimation and reward evaluation. Retrieved November 8, 2012, from https://openaccess.leidenuniv.nl/bitstream/handle/1887/14615/Chapter_4.pdf?sequence $=10$

Liu, N., Lim, J., \& Zhong, Y. (2007). Joint effects of gender composition, anonymity in communication and task type on collaborative learning. PACIS 2007 Proceedings, Paper 85.

Lizárraga, M. L., Baquedano, M. T., \& Cardelle-Elawar, M. (2007). Factors that affect decision making: gender and age differences. International Journal of Psychology and Psychological Therapy, 7(3), 381-391.

Lunenburg, F. C. (2011). Decision making in organizations. International Journal of Management, Business, and Administration, 15(1), 1-9.

Masuda, S., Sakagami, T., \& Hirota, S. (1997). Decision making be elderly people: Escape from choosing. Japanese Psychological Review, 40, 457-465.

Mather, M. M. N., Gorlick, M. A., Lighthall, N. R., Burgeno, J., Schoeke, A., \& Ariely, D. (2012). Risk Preferences and Aging: The 'Certainty Effect' in Older Adults' Decision Making (May 10, 2012). Psychology and Aging. Retrieved from http://ssrn.com/abstract=2055744 http://dx.doi.org/10.1037/a0030174

McIntyre, T. (2006).The new teachers and classroom behavior management. Retrieved February 11, 2012, from http://www.behaviouradvisor.com

Mercier, H., \& Sperber, D. (2011). Why do humans reason? Arguments for an argumentative theory. Behavioural and Brain Sciences, 34, 57-111. http://dx.doi.org/10.1017/S0140525X10000968

Narayan, S. M., \& Corcoran-Perry, S. (1997). Line of reasoning as a representation of nurses' clinical decision 
making. Research in Nursing \& Health, 20, 353-364. http://dx.doi.org/10.1002/(SICI)1098-240X(199708)20:4<353::AID-NUR8>3.0.CO;2-F

Pawlowski, B., \& Atwal, R. (2008). Sex differences in everyday risk-taking behavior in humans. Evolutionary Psychology, 6(1), 29-42.

Rana, M. H., Murtaza, S., Noor, F., \& Rehman, K. (2011). Effects of demographic factors on risky decision-making behaviour. European Journal of Social Sciences, 25(3), 69-76.

Rolison, J. J., Hanoch, Y., \& Wood, S. (2011). Risky decision making in younger and older adults: The role of learning. Psychology and Aging, 342, 1-12.

Rolison, J. J., Hanoch, Y., \& Wood, S. (2012). Risky decision making in younger and older adults. Psychology and Aging, 27(1), 129-140. http://dx.doi.org/10.1037/a0024689

Tsouloupas, C. N. (2011). Examining the perceptions of teachers' efficacy in handling student misbehavior in classroom and physical education settings. A Dissertation Submitted to the Graduate Faculty of the Louisiana State University and Agricultural and Mechanical College. Louisiana State, USA.

Van Leijenhorst, L., Westenberg, P. M., \& Crone, E. A. (2008). A developmental study of risky decisions on the cake gambling task: Age and gender analyses of probability estimation and reward evaluation. Developmental Neuropsychology, 33(2), 179-196. http://dx.doi.org/10.1080/87565640701884287

Yahaya, A., Ramli, J., Hashim, S., Ibrahim, A. M., Rahman, R. R., \& Yahaya, N. (2009). Discipline problems among secondary school students in Johor Bahru, Malaysia. European Journal of Social Sciences, 11(4), 659-675.

Zhu, H. (2009). Group polarization on corporate boards: Theory and evidence on board decisions about acquisition of premiums, executive compensation, and diversification. Journal of Operations Management, 27(6), 495-511.

\section{Copyrights}

Copyright for this article is retained by the author(s), with first publication rights granted to the journal.

This is an open-access article distributed under the terms and conditions of the Creative Commons Attribution license (http://creativecommons.org/licenses/by/3.0/). 